The production of bacteriostatic substances by the larger Basidiomycetes has been investigated ${ }^{11}$ by Wilkins and Harris, who state that their "results indicate that the larger Basidiomycetes are among the more promising fungus groups which produce antibiotics. . . "These authors, however, bese their opinion on the results of tests made mainly on $B$. coli and Staph. aureus.

There is a certain structural relationship between agaric acid and those synthetic acids which have been shown to be active against $M$. tuberculosis :<smiles>[R]C([R])C(=O)O</smiles><smiles>[R]C([R])(C)C([R])(C)CC(=O)O</smiles><smiles>[Y2]C(C(=O)O)C(O)(C(=O)O)C(=O)O</smiles>

Total number of $\mathrm{C}$ atoms in molecule:

$$
\begin{array}{ccc}
\text { (Adams) } & \text { (Robinson) } & \text { Agaric acid } \\
16-18 & 16-18 & 22
\end{array}
$$

The coincidences are too many to be overlooked, and in my opinion warrant $(a)$ a determination of the antibacterial activity of agaric acid towards $M$. tuberculosis, and $(b)$ an investigation of the synthesis and chemotherapy of related compounds. Both aspects of this investigation are in progress.

JoHN C. ROBERTS.

Department of Chemistry,

University College, Nottingham.

${ }^{2}$ Anderson, Chem. Rev., 29, 225 (1941).

"Adams et al., J. Amer. Chem. Soc., 51, 1261 (1929).

'Hook and Robinson, $J$. Chem. Soc., 152 (1944).

+ Vaudremer, Ann. Inst. Pasteur, 24, 189 (1910).

5 Soltys, Nature, 154, 550 (1944).

${ }^{6}$ Kallós, Nature, 155, 300 (1945).

'Smith and Emmart, Pub. Health Rep. (U.S. Pub. Health Service), 59, 417 (1944)

8 Miller and Rekate, Science, 100, 172 (1944).

- Thoms and Vogelsang, Ann. Chem., 357, 145 (1907).

${ }^{10}$ Passerini and Banti, Chem. Z., J, 1432 (1931).

${ }^{11}$ Wilkins and Harris, Ann. Appl. Biol., 31, 261 (1944).

\section{Acid Salts of Organic Acids as pH-Standards}

MaNy monobasic organic acids form crystalline acid sodium or potassium salts (for example, potassium hydrogen benzoate, $\mathrm{KC}_{7} \mathrm{H}_{5} \mathrm{O}_{2} \cdot \mathrm{HC}_{7} \mathrm{H}_{5} \mathrm{O}_{2}$ ). A solution of such a compound is equivalent to one of the acid half neutralized with a strong base, and it constitutes a buffer solution that is very readily prepared and that has a $p H$-value approximately equal to, but slightly lower than, $p K(=-\log K)$ for the acid. Their general usefulness is limited by the low solubilities of most organic acids, and by the comparatively restricted range of dissociation constants among acids otherwise suitable.

Preliminary measurements at $26^{\circ}$ show that $M / 50$ potassium hydrogen benzoate has $p H=4 \cdot 15$ and $M / 30$ potassium hydrogen phenylacetate $p H=4 \cdot 23$, the $p \mathrm{H}$ values being on the scale recommended by Hitchcock and Taylor ${ }^{1}$. These solutions are suggested as possible $p \mathrm{H}$-standards, and they are being further investigated from this point of view, together with other similar systems.

Potassium hydrogen phthalate has long been recognized as a $p \mathrm{H}$-standard, but this compound is not strictly analogous to those now suggested. Phthalic acid is dibasic; the buffering capacity of phthalic acid - caustic potash mixtures is actually at a minimum for the composition corresponding to $\mathrm{KHC}_{8} \mathrm{H}_{4} \mathrm{O}_{4}$ : and there is appreciable buffering only because $p \mathrm{~K}_{1}$ and $p \mathrm{~K}_{2}$ differ by not more than $2 \frac{1}{2}$ units. On the other hand, borax, which in solution is stoichiometrically equivalent to $\mathrm{NaBO} \mathrm{BO}_{2} \cdot \mathrm{HBO}_{2}$, gives a true buffer solution, and is an acid salt of the type discussed above.

\section{J. C. Speakman.}

Chemistry Department,

The University, Sheffield, 10.

March 26.

${ }^{1}$ J. Amer. Chem. Soc., 59, 1812 (1937) ; 60, 2710 (1938).

\section{Molar Polarization and Radius-Ratio of lons}

The interionic distance in the crystalline state is not exactly additive for the radii of the constituent ions. Fajans ${ }^{1}$ explains it in terms of polarization. Pauling ${ }^{2}$, on the other hand, neglecting the effect of polarization, explains these deviations from additivity as the effect of the radius-ratio, $p$, of the constituent cation to anion. In this communication a set of empirical equations concerning molar volumes and molar refractions of alkali halides will be first presented. Making use of these empirical equations, I am able to assign definite values to polarization and obtain a function of $\rho$ which, though different in form from Pauling's function, $F(\rho)$, gives identical values.

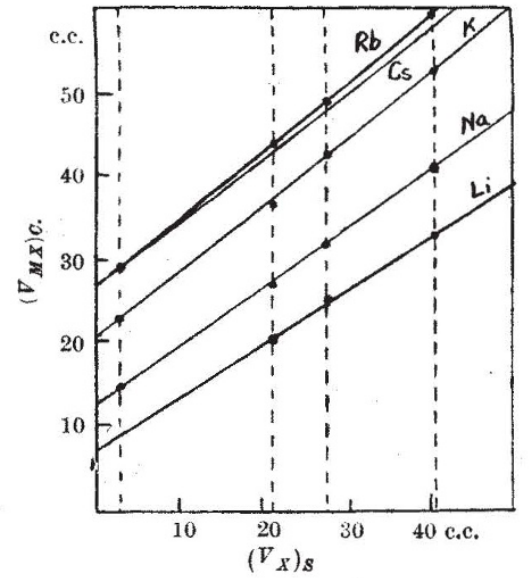

Fig. 1.

In plotting the molar volume ${ }^{3},\left(V_{M X}\right) C$, for halides of each alkali in the crystalline state against the volume of halide ions in solution of infinite dilution, $\left(V_{X}\right) s^{4,5}$, as shown in Fig. 1, a set of straight lines is obtained which can be expressed by the general equation :

$$
\left(V_{M X}\right)_{C}=a_{1}+b_{1}\left(V_{X}\right)_{S}, \quad \text {. }
$$

where $a_{1}$ and $b_{1}$ are characteristic constants for each cation.

I have previously'shown 6 that the volume, $(V)_{s}$, of ions in infinitely dilute solution is a linear function of the volume, $V$, calculated from Pauling's radii. Therefore $\left(V_{M X}\right)_{C}$ bears a linear relation with the volume of anions, $V_{X}$.

$$
\left(V_{M X}\right)_{C}=a_{2}+b_{2} V_{X}
$$

